\title{
Geographical Variation in Health-Related Quality of Life Among Older US Adults, 1997-2010
}

Diana Kachan, BS; Stacey L. Tannenbaum, PhD; Henry A. Olano, BA; William G. LeBlanc, PhD; Laura A. McClure, MSPH; David J. Lee, PhD

Suggested citation for this article: Kachan D, Tannenbaum SL, Olano HA, LeBlanc WG, McClure LA, Lee DJ. Geographical Variation in Health-Related Quality of Life Among Older US Adults, 1997-2010. Prev Chronic Dis 2014;11:140023. DOI: http://dx.doi.org/10.5888/pcd11.140023 圈.

PEER REVIEWED

\section{Abstract}

\section{Introduction}

Health-related quality of life (HRQOL) is an important predictor of morbidity and mortality; however, its geographical variation in older adults in the United States has not been characterized. We compared HRQOL among older adults in the 50 US states and the District of Columbia using the Health and Activities Limitation Index (HALex). We also compared the HRQOL of 4 regions: South, West, Midwest, and Northeast.

\section{Methods}

We analyzed pooled data from 1997 through 2010 from the National Health Interview Survey for participants aged 65 or older. HALex scores (which range from o to 1.0o, with higher values indicating better health) were calculated by combining data on participants' perceived health and activity limitations. We ranked states by mean HALex score and performed multivariable logistic regression analyses to compare low scores (defined as scores in the lowest quintile) among US regions after adjustment for sociodemographics, health behaviors, and survey design.

\section{Results}

Older residents of Alaska, Alabama, Arkansas, Mississippi, and West Virginia had the lowest mean HALex scores (range, 0.62-0.68); residents of Arizona, Delaware, Nevada, New Hampshire, and Vermont had the highest mean scores (range, 0.78-0.79). Residents in the Northeast (odds ratio [OR], 0.66; 95\% confidence interval [CI], 0.57-0.76) and the Midwest (OR, 64; 95\% CI, 0.56-0.73) were less likely than residents in the South to have scores in the lowest quintile after adjustment for sociodemographics, health behaviors, and survey design.

\section{Conclusion}

Significant regional differences exist in HRQOL of older Americans. Future research could provide policy makers with information on improving HRQOL of older Americans.

\section{Introduction}

Health-related quality of life (HRQOL) is predictive of mortality in older adults (1), and it is a newly measurable target for improvement in Healthy People 2020 (2). The HRQOL of some older adults, such as those who have arthritis, has been characterized (3), and an association between the HRQOL of older adult population groups and health factors such as physical activity $(4,5)$ and obesity $(6,7)$ has been established.

Studies show a regional variation in the health behaviors of older adults. For example, 1 study found state variations in smoking, drinking, and physical activity levels among older adults (8). A study of Medicare beneficiaries in 2002 showed a regional variation in the functional status of older adults, with those residing in the southern US states reporting greater functional limitations (9). Regional variation in obesity status has also been recognized (10). Older adults living in southern states were found to have the lowest healthy life expectancy (11). Nationally representative data were used to examine geographical variation in the self-rated health of older US adults (12). For the general population, an HRQOL measure derived from the number of healthy days was used to examine state variation in 
HRQOL (13). However, geographic variation in HRQOL of older adults has not been examined. The objective of our study was to use a nationally representative data set and the Health and Activities Limitation Index (HALex) to compare HRQOL among adults aged 65 or older in the 50 states and the District of Columbia. We also compared HRQOL for 4 regions of the United States: West, Midwest, South, and Northeast (14).

\section{Methods}

We pooled data from 1997 through 2010 from the National Health Interview Survey (NHIS), an annual multistage probability household survey of the US civilian noninstitutionalized population. We included participants aged 65 or older ( $\mathrm{n}=79,863$, representing approximately $34,587,284$ people). HALex scores were calculated according to methods described by Livingston and Ko (14); scores range from o to 1.00, with lower scores reflecting poorer HRQOL. Calculation of HALex scores is based on participants' responses to questions about their health and activity limitations, including the following: needing help with personal care and routine needs, being unable to work because of a health problem, being limited in the kind or amount of work that the participant is able to perform, and being limited in any other way.

We ranked states by calculated mean HALex score and sorted states by mean score. We used multivariable logistic regression to compare low HALex scores (defined as scores in the lowest quintile) among US regions (South, West, Midwest, and Northeast); we used the South as the reference group. States were assigned to regions according to the 2010 US Census classification (15) (Figure). Regression analyses were adjusted for the following sociodemographic variables: as continuous variables, age and body mass index; and as categorical variables, sex, race/ethnicity (nonHispanic black, non-Hispanic white, Hispanic, or other), education (less than a high school degree, high school degree or equivalent, or more than a high school degree), health insurance status (has insurance or does not have insurance), employment status (employed or unemployed), smoking and drinking history (current, former, or never for each), and compliance with the American College of Sports Medicine and the American Heart Association recommendations for physical activity (yes or no) (16). Compliance is defined as performing moderate physical activity for 30 minutes or more per day for 5 or more days per week or vigorous physical activity for 20 minutes or more per day for 3 or more days per week (16). Sampling weights were used to adjust for survey design (17). All analyses were conducted in SAS version 9.2 (SAS Institute Inc, Cary, North Carolina). Because state data were not publically available, analyses were performed at the National Center for Health Statistics Research Data Center in Hyattsville, Maryland, by a member of the research team (W.G.L.). This study was approved by the University of Miami Institutional Review Board.

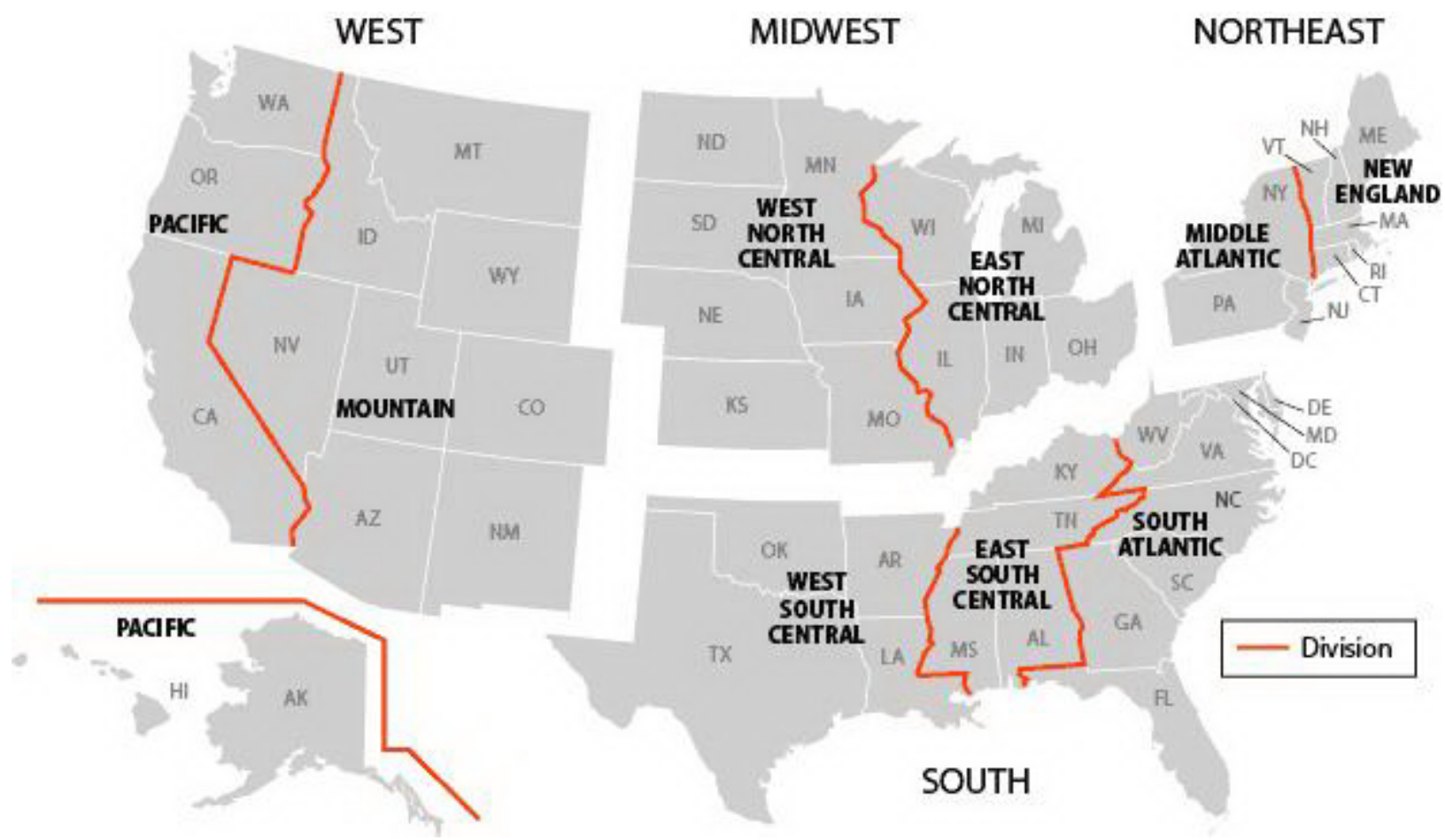

Figure. States were grouped into West, Midwest, Northeast, and South, according to US Census regions and divisions (15). [A text description of this figure is also available.]

\section{Results}


The mean HALex score for older US adults was 0.735 (standard error, o.oo1, Table 1). Residents of Alaska, Alabama, Arkansas, Mississippi, and West Virginia had the lowest mean HALex scores (range, 0.62-0.68), whereas residents of Arizona, Delaware, Nevada, New Hampshire, and Vermont had the highest scores (range, o.78-0.79) (Table 1). Residents of the Northeast (odds ratio [OR], o.66; 95\% confidence interval [CI], o.57-0.76) and Midwest (OR, o.64; 95\% CI, 0.56-0.73) were less likely than residents of the South to be in the lowest quintile of HALex scores after adjustment for sociodemographics, health behaviors, and survey design (Table 2)

\section{Discussion}

We found variation in HRQOL among regions and states. Scores ranged from 0.62 (Alaska) to 0.79 (Delaware), the former score representing on average an inability to perform a major activity (such as an activity of daily living) and the latter representing a partial limitation in a nonessential activity (18). Older adults in the South were more likely to have the lowest HRQOL scores than were their Northeast and Midwest counterparts even after adjustment for sociodemographic factors and health behaviors. State ranking by mean HALex score showed a similar pattern: most of the lowest-ranking states were located in the South. Studies show that older adults in southern states have high rates of disability, mobility issues, and functional limitations $(9,19,20)$ as well as risk factors for poor functional status (diabetes [21], stroke [22,23], obesity [10], and hypertension [24]). Higher disability rates persist among older adults who migrate from the South to other regions $(20,25)$. Better prevention of disability risk factors in the general population of the South could help improve HRQOL of older adults in that region.

The pattern of low HALex scores in the South and higher scores in other regions is not totally consistent. For example, Delaware (included as a southern state in this study) ranked the highest of all states, and Florida ranked 14th, far above all other southern states. In other studies, Florida showed evidence of not being similar to other southern states - older residents of Florida have a higher life expectancy (11), a lower prevalence of smoking, and a higher prevalence of compliance with daily physical activity recommendations (8) than older residents of other southern states. Older adults in Delaware are also among the most likely to meet the daily requirements for physical activity and have a higher life expectancy than residents of other southern states (except Florida). Alaska ranked 51st in our study. Older residents of Alaska have the highest prevalence of risky drinking of all states; however, their life expectancy is comparable with the life expectancy for residents of the West and Midwest $(8,11)$.

Among the potential explanations for the inconsistent rankings of Delaware and Alaska is the HALex calculation. The index includes measures of functional limitations, and therefore it depends on the individual's physical limitations as well as the individual's access to transportation, services, and assistive devices. HALex tends to give more biased (ie, lower) measures for people with disabilities than some other HRQOL scores $(26,27)$. A study of Medicare beneficiaries suggested that a higher prevalence of functional limitations among older women in the South could be attributed to areas of lower population density with higher poverty levels (9). Although Delaware and Alaska are among the top 15 states for highest median household income (28), Delaware has the 6th-highest population density in the United States and an award-winning public transportation system complete with a state-wide door-to-door paratransit service for the elderly (29,30). Alaska has the lowest population density in the United States and a public transportation system that is not easily accessible (29). Although differences in HALex scores between states can be partially explained by the relative ease of getting around and differences in the levels of physical activity and alcohol consumption, further research is necessary to examine other potential causes of such differences.

Our state rankings differed from a previous Behavioral Risk Factor Surveillance System (BRFSS)-based study of the general adult population (13), especially for the highest HRQOL scores; however, rankings were similar for the lowest HRQOL scores. The BRFSS study used the Healthy Days measure to derive a utility-based index similar to HALex, and the authors noted that the validity of such derivation has not been determined. Our study used a validated HRQOL measure that was created for use with NHIS data, and therefore it is a more valid representation of the actual HRQOL of the study participants. In addition, some of the inconsistencies in state rankings between the general adult BRFSS study and our older adult study may result from differences in perceptions of perfect health between participants of different age groups and from differences in accommodations accessible to adults of different ages (such as services available through Medicare or state-funded services for older adults). These differences would have affected the HALex measurements of self-rated health and functional limitations. Finally, such differences could have resulted from the limitations of the data. NHIS is not designed as a state survey, and BRFSS has low response rates. Findings from both data sources might complement each other in assessing population needs in future studies.

Significant regional variation exists in the HRQOL of older individuals in the United States. Measures aimed at improving the HRQOL of older adults are warranted in southern states and in Alaska.

\section{Acknowledgments}


This work was supported by Bankhead Coley Cancer Research Program (grant no. 1BGo6-341963), the National Institute for Occupational Safety and Health (grant no. Ro1OH03915), and the National Institute on Aging (grant no. F30AG040886).

\section{Author Information}

Corresponding Author: Diana Kachan, BS, Department of Public Health Sciences, University of Miami Miller School of Medicine, 1120 NW 14th St, Room 1073, Miami, FL 33136. Telephone: 305-243-7565. E-mail:

dkachan@med.miami.edu.

Author Affiliations: Stacey L. Tannenbaum, Henry A. Olano, William G. LeBlanc, Laura A. McClure, David J. Lee, University of Miami Miller School of Medicine, Miami, Florida.

\section{References}

1. Dominick KL, Ahern FM, Gold CH, Heller DA. Relationship of health-related quality of life to health care utilization and mortality among older adults. Aging Clin Exp Res 2002;14(6):499-508. CrossRef 国 PubMed 圈

2. US Department of Health and Human Services. Healthy People 2020 objectives. Washington (DC): US Department of Health and Human Services; 2011.

3. Dominick KL, Ahern F, Gold C, Heller D. Health-related quality of life among older adults with arthritis. Health Qual Life Outcomes 2004;2(1):5. CrossRef 圂 PubMed 圈

4. Rejeski WJ, Mihalko SL. Physical activity and quality of life in older adults. J Gerontol A Biol Sci Med Sci 2001;56 (Spec No 2):23-35. CrossRef圈 PubMed 圈

5. Bize R, Johnson JA, Plotnikoff RC. Physical activity level and health-related quality of life in the general adult population: a systematic review. Prev Med 2007;45(6):401-15. CrossRef 圈 PubMed 圈

6. Jia H, Lubetkin EI. The impact of obesity on health-related quality-of-life in the general adult US population. $\mathrm{J}$ Public Health (Oxf) 2005;27(2):156-64. CrossRef 国 PubMed 圈

7. Yan LL, Daviglus ML, Liu K, Pirzada A, Garside DB, Schiffer L, et al. BMI and health-related quality of life in

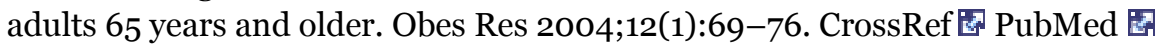

8. Tannenbaum SL, Kachan D, Fernandez CA, McClure LA, LeBlanc WG, Arheart KL, et al. State variations of chronic disease risk factors in older Americans. Prev Chronic Dis 2012;9: CrossRef 国 PubMed 国

9. Porell FW, Miltiades HB. Regional differences in functional status among the aged. Soc Sci Med 2002;54(8):118198. CrossRef 国 PubMed 医

10. Wang Y, Beydoun MA. The obesity epidemic in the United States - gender, age, socioeconomic, racial/ethnic, and geographic characteristics: a systematic review and meta-regression analysis. Epidemiol Rev 2007;29(1):6-28. CrossRef 圈 PubMed 圈

11. Centers for Disease Control and Prevention. State-specific healthy life expectancy at age 65 years - United States, 2007-2009. MMWR Morb Mortal Wkly Rep 2013;62(28):561-6. PubMed 圈

12. Campbell VA, Crews JE, Moriarty DG, Zack MM, Blackman DK. Surveillance for sensory impairment, activity limitation, and health-related quality of life among older adults - United States, 1993-1997. MMWR CDC Surveill Summ 1999;48(8):131-56. PubMed 圈

13. Jia H, Lubetkin EI. The statewide burden of obesity, smoking, low income and chronic diseases in the United States. J Public Health (Oxf) 2009;31(4):496-505. CrossRef 国 PubMed 国

14. Livingston EH, Ko CY. Use of the health and activities limitation index as a measure of quality of life in obesity. Obes Res 2002;10(8):824-32. CrossRef 圈 PubMed 圈

15. Census regions and divisions of the United States. US Census Bureau. http://www.census.gov/geo/mapsdata/maps/pdfs/reference/us_regdiv.pdf. Accessed May 1, 2014.

16. Haskell WL, Lee I-M, Pate RR, Powell KE, Blair SN, Franklin BA, et al. Physical activity and public health: updated recommendation for adults from the American College of Sports Medicine and the American Heart Association. Circulation 2007;116(9):1081. CrossRef 国 PubMed 国

17. Botman SL, Jack SS. Combining National Health Interview Survey datasets: issues and approaches. Stat Med 1995;14(5-7):669-77. CrossRef 圈 PubMed 圈

18. Erickson P. Evaluation of a population-based measure of quality of life: the Health and Activity Limitation Index (HALex). Qual Life Res 1998;7(2):101-14. CrossRef 国 PubMed 圈

19. Lin G. Regional assessment of elderly disability in the U.S. Soc Sci Med 2000;50(7-8):1015-24. CrossRef 园 PubMed 因 
20. Lin G, Zimmer Z. A geographical analysis of spatial differentials in mobility and self-care limitations among older Americans. Int J Popul Geogr 2002;8(6):395-408. CrossRef 国

21. Mokdad AH, Ford ES, Bowman BA, Nelson DE, Engelgau MM, Vinicor F, et al. Diabetes trends in the U.S.: 19901998. Diabetes Care 2000;23(9):1278-83. CrossRef 圈 PubMed 圈

22. Lanska DJ. Geographic distribution of stroke mortality in the United States: 1939-1941 to 1979-1981. Neurology 1993;43(9):1839. CrossRef 圈 PubMed 圈

23. Casper ML, Wing S, Anda RF, Knowles M, Pollard RA. The shifting stroke belt: changes in the geographic pattern of stroke mortality in the United States, 1962 to 1988. Stroke 1995;26(5):755-60. CrossRef 圈 PubMed 国

24. Obisesan TO, Vargas CM, Gillum RF. Geographic variation in stroke risk in the United States: region, urbanization, and hypertension in the third National Health and Nutrition Examination Survey. Stroke 2000;31 (1):19-25. CrossRef 国 PubMed 圈

25. Kington R, Carlisle D, McCaffrey D, Myers H, Allen W. Racial differences in functional status among elderly U.S. migrants from the South. Soc Sci Med 1998;47(6):831-40. CrossRef 圈 PubMed 圈

26. Boslaugh SE, Andresen EM, Recktenwald A, Gillespie K. Evidence for potential bias in the Health and Activity Limitation Index as a health preference measure for persons with disabilities. Disabil Health J 2009;2(1):20-6. CrossRef 圈 PubMed 圈

27. Truman BI, Smith C, Roy K, Chen Z, Moonesinghe R, Zhu J, et al. Rationale for regular reporting on health disparities and inequalities - United States. MMWR Surveill Summ 2011;60(1):3-10. PubMed

28. United States Census Bureau. State median income: 2009-2011.

http://www.census.gov/hhes/www/income/data/statemedian/. Accessed October 19, 2013.

29. United States Census Bureau. State totals: vintage 2012.

http://www.census.gov/popest/data/state/totals/2012/index.html. Accessed October 19, 2013.

30. Solutions V. Delaware Transit Corporation case study. http://vigil-

solutions.com/pdfs/Delaware_Case_Study.pdf. Accessed August 16, 2013.

\section{Tables}

Table 1. Mean Health and Activities Limitation Indexa Scores, by State, Participants Aged 65 or Older, National Health Interview Survey, 19972010

\begin{tabular}{|l|r|r|r|r|}
\hline State & Sample Size & Estimated Population & Mean Score (SE) & Rank \\
\hline All states & 79,863 & $34,587,284$ & $0.735(0.001)$ & NA \\
\hline Alabama & 1,533 & 662,542 & $0.657(0.009)$ & 50 \\
\hline Alaska & 73 & 38,676 & $0.616(0.049)$ & 51 \\
\hline Arizona & 1,427 & 646,305 & $0.779(0.010)$ & 4 \\
\hline Arkansas & 965 & 432,278 & $0.680(0.019)$ & 47 \\
\hline California & 8,343 & $3,265,104$ & $0.733(0.004)$ & 31 \\
\hline Colorado & 926 & 391,420 & $0.766(0.008)$ & 10 \\
\hline Connecticut & 1,036 & 467,428 & $0.754(0.010)$ & 15 \\
\hline District of Columbia & 204 & 71,562 & $0.715(0.024)$ & 37 \\
\hline Delaware & 218 & 109,028 & $0.788(0.018)$ & 1 \\
\hline Florida & 6,155 & $2,579,298$ & $0.756(0.005)$ & 14 \\
\hline Georgia & 1,863 & 818,102 & $0.721(0.008)$ & 35 \\
\hline Hawaii & 478 & 198,790 & $0.752(0.009)$ & 16 \\
\hline Idaho & 308 & 141,044 & $0.728(0.011)$ & 33 \\
\hline Illinois & 3,349 & $1,483,862$ & $0.749(0.005)$ & 18 \\
\hline & & & &
\end{tabular}


Preventing Chronic Disease | Geographical Variation in Health-Related Quality of Life A... Page 6 of 7

\begin{tabular}{|c|c|c|c|c|}
\hline State & Sample Size & Estimated Population & Mean Score (SE) & Rank \\
\hline Indiana & 1,696 & 743,281 & $0.744(0.010)$ & 24 \\
\hline Iowa & 872 & 386,691 & $0.760(0.011)$ & 12 \\
\hline Kansas & 793 & 332,663 & $0.740(0.013)$ & 26 \\
\hline Kentucky & 1,148 & 523,258 & $0.686(0.007)$ & 45 \\
\hline Louisiana & 1,189 & 508,999 & $0.708(0.010)$ & 42 \\
\hline Maine & 458 & 223,202 & $0.749(0.011)$ & 19 \\
\hline Maryland & 1,253 & 590,046 & $0.748(0.008)$ & 21 \\
\hline Massachusetts & 1,843 & 850,085 & $0.772(0.008)$ & 9 \\
\hline Michigan & 2,775 & $1,222,078$ & $0.734(0.007)$ & 30 \\
\hline Minnesota & 1,236 & 572,982 & $0.772(0.006)$ & 8 \\
\hline Mississippi & 828 & 363,832 & $0.669(0.019)$ & 48 \\
\hline Missouri & 1,766 & 789,941 & $0.705(0.009)$ & 43 \\
\hline Montana & 306 & 124,147 & $0.730(0.022)$ & 32 \\
\hline Nebraska & 613 & 280,481 & $0.772(0.018)$ & 7 \\
\hline Nevada & 473 & 211,611 & $0.787(0.010)$ & 3 \\
\hline New Hampshire & 320 & 162,612 & $0.788(0.017)$ & 2 \\
\hline New Jersey & 2,467 & $1,121,428$ & $0.751(0.005)$ & 17 \\
\hline New Mexico & 767 & 237,822 & $0.715(0.013)$ & 38 \\
\hline New York & 5,449 & $2,205,410$ & $0.749(0.005)$ & 20 \\
\hline North Carolina & 2,303 & $1,050,880$ & $0.708(0.007)$ & 41 \\
\hline North Dakota & 263 & 107,990 & $0.738(0.022)$ & 27 \\
\hline Ohio & 3,327 & $1,538,785$ & $0.720(0.006)$ & 36 \\
\hline Oklahoma & 1,031 & 457,966 & $0.708(0.019)$ & 40 \\
\hline Oregon & 992 & 445,257 & $0.744(0.013)$ & 25 \\
\hline Pennsylvania & 3,762 & $1,797,310$ & $0.746(0.006)$ & 23 \\
\hline Rhode Island & 261 & 136,223 & $0.763(0.020)$ & 11 \\
\hline South Carolina & 1,223 & 567,687 & $0.715(0.008)$ & 39 \\
\hline South Dakota & 293 & 139,407 & $0.735(0.024)$ & 29 \\
\hline Tennessee & 1,515 & 670,593 & $0.681(0.010)$ & 46 \\
\hline Texas & 5,192 & $1,881,478$ & $0.704(0.005)$ & 44 \\
\hline Utah & 522 & 268,451 & $0.737(0.010)$ & 28 \\
\hline Vermont & 148 & 70,843 & $0.777(0.014)$ & 5 \\
\hline Virginia & 1,991 & 929,455 & $0.728(0.012)$ & 34 \\
\hline Washington & 1,438 & 648,596 & $0.758(0.008)$ & 13 \\
\hline West Virginia & 572 & 265,964 & $0.663(0.020)$ & 49 \\
\hline Wisconsin & 1,737 & 781,984 & $0.775(0.005)$ & 6 \\
\hline Wyoming & 163 & 72,406 & $0.747(0.023)$ & 22 \\
\hline
\end{tabular}

Abbreviations: SE, standard error; NA, not applicable.

a Scores range from 0 to 1.00 , with higher values indicating better health (14). 
Preventing Chronic Disease | Geographical Variation in Health-Related Quality of Life A... Page 7 of 7

Table 2. Likelihood of Being in the Lowest Quintile of HALexa Scores, Participants Aged 65 Years or Older, National Health Interview Survey, 1997-2010

\begin{tabular}{|c|c|c|}
\hline Covariate & $\begin{array}{l}\text { Odds Ratio ( } 95 \% \\
\text { Confidence Interval) }\end{array}$ & $\begin{array}{c}P \\
\text { Value }\end{array}$ \\
\hline Age & $1.05(1.04-1.05)$ & $<.001$ \\
\hline Body mass index & $1.03(1.02-1.04)$ & $<.001$ \\
\hline Female vs male & $1.14(1.02-1.27)$ & .026 \\
\hline Uninsured vs insured & $0.99(0.56-1.74)$ & .96 \\
\hline Employed vs unemployed & $0.07(0.04-0.14)$ & $<.001$ \\
\hline \multicolumn{3}{|l|}{ Race } \\
\hline Black vs non-Hispanic white & $1.24(1.09-1.42)$ & .002 \\
\hline Hispanic vs non-Hispanic white & $1.21(1.02-1.43)$ & .03 \\
\hline Other vs non-Hispanic white & $1.22(0.91-1.64)$ & .19 \\
\hline \multicolumn{3}{|l|}{ Education } \\
\hline High school degree vs more than high school degree & $1.08(0.93-1.24)$ & .31 \\
\hline Less than high school degree vs more than high school degree & $1.65(1.46-1.87)$ & $<.001$ \\
\hline \multicolumn{3}{|l|}{ Smoking status } \\
\hline Current smoker vs nonsmoker & $1.59(1.34-1.89)$ & $<.001$ \\
\hline Former smoker vs nonsmoker & $1.46(1.30-1.65)$ & $<.001$ \\
\hline \multicolumn{3}{|l|}{ Use of alcohol } \\
\hline Current drinker vs nondrinker & $0.32(0.28-0.38)$ & $<.001$ \\
\hline Former drinker vs nondrinker & $1.01(0.90-1.14)$ & .88 \\
\hline $\begin{array}{l}\text { Does not meet physical activity recommendations of Healthy People } \\
2010 \text { vs does meet recommendations }\end{array}$ & $9.56(7.20-12.68)$ & $<.001$ \\
\hline \multicolumn{3}{|l|}{ Region } \\
\hline West vs South & $0.92(0.79-1.08)$ & .32 \\
\hline Midwest vs South & $0.64(0.56-0.73)$ & $<.001$ \\
\hline Northeast vs South & $0.66(0.57-0.76)$ & $<.001$ \\
\hline
\end{tabular}

a Health and Activities Limitations Index (14).

The opinions expressed by authors contributing to this journal do not necessarily reflect the opinions of the U.S. Department of Health and Human Services, the Public Health Service, the Centers for Disease Control and Prevention, or the authors' affiliated institutions.

For Questions About This Article Contact pcdeditor@cdc.gov

Page last reviewed: July 03, 2014

Page last updated: July 03, 2014

Content source: National Center for Chronic Disease Prevention and Health Promotion

Centers for Disease Control and Prevention 1600 Clifton Rd. Atlanta, GA 30333, USA

80o-CDC-INFO (80o-232-4636) TTY: (888) 232-6348 - Contact CDC-INFO 